23

\title{
Создание ZnO нанокатализатора, фиксированного на подложке, и перспективы фотокаталитического получения биогаза
} из растительных отходов

\author{
(С) И.Ю. Денисюк, Д.А. Морозова, Ю.А. Игнатьева, М.В. Успенская
}

Университет ИТМО, 1971101 Санкт-Петербург, Россия

e-mail: denisiuk@mail.ifmo.ru

Поступила в редакцию 27.12.2020 г.

В окончательной редакции 27.12.2020 г.

Принята к публикации 07.02.2021 г.

Рассмотрено получение биотоплива из сельскохозяйственных отходов, таких как сахара, спирты, органические кислоты, путем получения из них водорода и биогаза при фотокаталитическом разложении. Представлены возможные химические реакции при фотокатализе на примере фотокаталитического разложения метанола на водород и двуокись углерода. Проведены эксперименты по получению наноструктурированного $\mathrm{ZnO}$ гидротермальным методом в растворе, содержащем цинк ацетат и уротропин. Полученный $\mathrm{ZnO}$, иммобилизированный на подложке, предполагается использовать в качестве фотокатализатора. Рассмотрена возможная конструкция реакционного сосуда и источники излучения для лабораторной установки получения биогаза из модельных растворов.

Ключевые слова: фотокатализ, биогаз, $\mathrm{ZnO}$, нанопроволоки, утилизация отходов, возобновляемая энергетика.

DOI: 10.21883/OS.2021.06.50994.314-20

\section{Введение}

Возобновляемая энергетика является одним из основных трендов современности. Она предполагает как получение энергии из природных источников - солнечный свет, ветер, приливы, так и использование сельскохозяйственных отходов для производства биотоплива и биогаза. Использование и переработка сельскохозяйственных отходов актуальны также в связи с загрязнением окружающей среды. Так, отходы производства сахара из сахарной свеклы составляют до 90\% начальной биомассы и загрязняют окружающую среду органическими кислотами [1]. Свекловичный жом классифицируется как отходы пятого класса опасности. Размещение этого типа отходов на полях без переработки и соответствующей обработки приводит к разрушению экосистем на пять лет и более. Отходы маниоки еще более токсичны и загрязняют окружающую среду цианидами, поэтому их переработка в биотопливо позволяет уменьшить загрязнение окружающей среды [2]. В общем плане отходами переработки сельскохозяйственной продукции является ряд веществ, таких как крахмал, органические кислоты, сахара, а в случае ферментации они преобразуются в смесь спиртов, в которой присутствуют метиловый, этиловый и другие спирты, а в случае маниоки еще и цианиды. Все эти компоненты токсичны, но могут быть переработаны в топливо.

В течение последнего десятка лет основной процесс утилизации отходов базируется на брожении с получением биоэтанола с примесью метанола и других продук- тов, получаемых, главным образом, путем ферментации биомассы. Из биоэтанола может быть получен биогаз и водород как основное биотопливо. Водород получают из биоэтанола методом низкотемпературной конверсии (риформинга) на катализаторе Rh и Ni в газовой фазе [3]. Обычно эти катализаторы используются на микродисперсном носителе, таком как $\mathrm{MgO}, \mathrm{ZnO}, \mathrm{CeO}_{2}$, которые повышают эффективность катализа [3]. Недостаток традиционного подхода - необходимость проведения риформинга биоэтанола при высокой температуре, что усложняет процесс и требует дополнительных энергозатрат, как для получения биоэтанола из агрохимических отходов, так и для его риформинга в водород. Второй недостаток - токсичные отходы, в частности цианиды, загрязняют почву.

В последние годы появился ряд публикаций, в которых рассматривается возможность прямого получения водорода и биогаза из биомассы после ее ферментации без выделения биоэтанола путем проведения фотоэлектрохимических реакций на катализаторе в жидкой фазе без нагрева. Данный процесс имеет неоспоримое преимущество, заключающееся в простоте реализации и малых энергозатратах, необходимых для получения водорода. При этом становится возможным использование и других продуктов ферментирования биомассы, а токсичные вещества окисляются и переводятся в нетоксичную форму. В работе [4] рассмотрен процесс фотоэлектрохимического окисления глюкозы, получаемой из биомассы на катализаторе из нанотрубок $\mathrm{Ti} / \mathrm{TiO}_{2}$. Обнаружен процесс окисления, который проис- 
ходит непосредственно путем фотогенерации дырок на поверхности полупроводника и переноса электрона с молекулы глюкозы на фотокатализатор с ее окислением. В эксперименте была получена электрохимическая конверсия 78\% глюкозы. Имеются подобные публикации, в которых рассматриваются процессы получения водорода подобными методами, а также и перевода токсичных отходов в нетоксичную форму.

Все фотоэлектрохимические каталитические методы окисления базируются на использовании нанокатализаторов, выполненные обычно в виде наностержней, нанопроволок, имеющих большую удельную поверхность. Способ получения таких нанокатализаторов должен обеспечивать формирование однородной плотно упакованной структуры наноэлементов в результате физикохимического процесса, что позволяет получать большие поверхности катализатора. Например, ряд методов получения нанотрубок $\mathrm{TiO}_{2}$ описан в работе [5]. Хотя в этом случае гидротермальные и химические способы и обеспечивают получение нитей оксида нанометрового диаметра с большим удлинением, но нити оказываются перепутаны, многие не имеют контакта с подложкой и однонаправленный перенос электронов и дырок, необходимый для фотоэлектрохимического катализа, оказывается невозможным. Формирование ориентированных упорядоченных нанотрубок, направленных перпендикулярно подложке и имеющих с ней электрический контакт, описанное в том же обзоре, обеспечивает метод анодирования фольги титана. Такая структура может обеспечить направленный перенос носителей заряда. Второй эффективный метод формирования наностержней, упорядоченных и ориентированных перпендикулярно подложке был описан в работе [6]. Метод основан на использовании подложки со слоем адсорбированных кристаллов $\mathrm{ZnO}$ и контролируемой реакцией разложения ацетата цинка с получением нанопроволок $\mathrm{ZnO}$ с плотной упаковкой, ориентированных перпендикулярно подложке и потенциально способных выполнять фотоэлектрохимический катализ в процессе получения водорода.

Таким образом, современное состояние исследований показывает возможность формирования плотных упорядоченных структур нанопроволок и наностержней, расположенных перпендикулярно подложке и потенциально обеспечивающих однонаправленный перенос фотоносителей в фотоэлектрохимической ячейке, положенной в основу проекта. Однако для его реализации необходимо модифицировать общую идею нанокатализатора, обеспечив формирование упорядоченного массива нанопроволок на требуемой подложке, при легировании примесями, обеспечивающими требуемый каталитический эффект, провести исследования основных как физических, так и фотохимических процессов на созданной структуре.

\section{Экспериментальные результаты и их обсуждение}

Процесс фотокаталитического расщепления молекул глюкозы, спиртов и других веществ на поверхности широкозонного полупроводника заключается в фотогенерации электронно-дырочной пары при поглощении кванта света полупроводником, выхода электрона и дырки на поверхность и прохождения химической реакции, индуцированной электроном и дыркой, имеющими высокую энергию относительно равновесного значения. В последние десятилетия фотоэлектрохимические процессы на поверхности наночастиц исследуются применительно к фотоэлектрохимическим солнечным элементам и для других применений (см., например, обзор [7]), а в нашей работе [8] рассмотрен фотоэлектрохимический процесс на поверхности наночастиц $\mathrm{ZnO}$ как способ разрушения полимерных пленок после их использования для упаковки. В качестве широкозонного полупроводника с шириной зоны около $2 \mathrm{eV}$ обычно используют $\mathrm{TiO}_{2}$, $\mathrm{ZrO}_{2}, \mathrm{ZnO}$.

Процесс фотокаталитического получения биогаза и водорода целесообразен только при использовании высокоэффективных светодиодов диапазона $380-450 \mathrm{~nm}$. Применение таких диодов определяется спектральной зависимостью фотоэлектрохимической реакции на поверхности полупроводника, измерить которую весьма затруднительно. Однако, исходя из физики процесса она должна коррелировать с фотопроводимостью порошка полупроводника, в частности $\mathrm{ZnO}$. Спектр фотопроводимости в порошке $\mathrm{ZnO}$ приведен в работе [9]. Как видно из спектра фотопроводимости имеется значительная величина фототока, коррелирующая с эффективностью фотогенерации носителей в области длин волн 400-450 nm. Это позволяет использовать для фотолиза современные высокоэффективные светодиоды с длиной волны излучения $405 \mathrm{~nm}$ и мощностью $3 \mathrm{~W}$, например EPILED Ultra violet 3W High Power Led на основе GaN, имеющий высокий квантовый выход и интенсивность излучения 6-10 лм. Собственно, именно высокая эффективность современных излучающих диодов и позволяет реализовать фотолитическое преобразование глюкозы, спиртов и других отходов в водород с достаточной эффективностью, в то время как имеющиеся ранее источники коротковолнового излучения, такие как ртутные лампы не имели достаточной энергоэффективности, и реализация этого процесса была технически нецелесообразна.

Конструкция фотоэлектрохимической лабораторной ячейки, собранной в лаборатории, использующей нанокатализатор и обеспечивающей получение биоводорода из раствора глюкозы либо спиртов, представлена на рис. 1.

Ячейка представляет собой емкость (промывочная склянка), в которую вводится раствор реагентов - спирты, глюкоза. Рядом с промывочной склянкой размещен светодиод с ультрафиолетовым излучением с длиной 


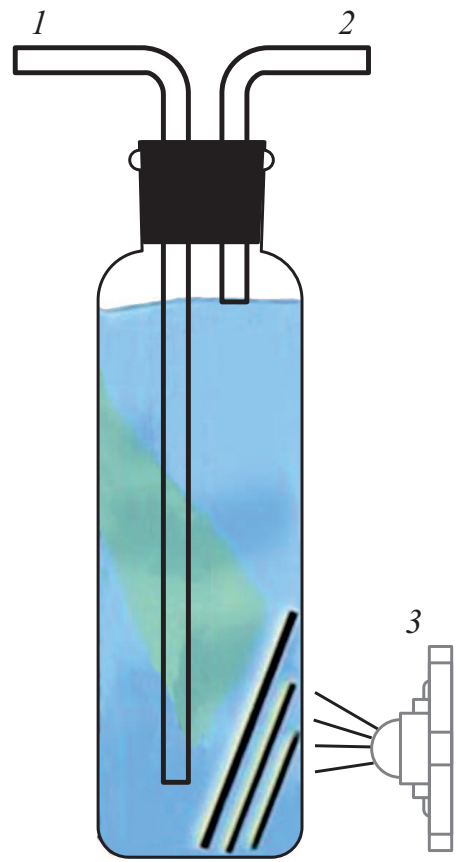

Рис. 1. Схема ячейки для проведения фотокатализа. 1 - выход на газометр, 2 - выход, 3 - коротковолновый светодиод.

волны $405 \mathrm{~nm}$ и мощностью $3 \mathrm{~W}$. Фотокатализатор в виде $\mathrm{ZnO}$ нанопроволок, выращенных на подложке, на поверхности которых и происходит фотолиз, размещен внутри склянки в растворе. Образующийся газ собирается в выводную трубку, для инфракрасного анализа и определение скорости его генерации. Вся система закрыта алюминиевой фольгой для увеличения эффективности использования ультрафиолетового излучения и защиты от его выхода в окружающее пространство.

Ожидаемыми растворимыми углеводородами, получаемыми из отходов сельскохозяйственной продукции, являются: глюкоза, полисахариды, спирты, органические кислоты. Рассмотрим процессы их фотохимического разрушения. Процесс фотолитического разложения глюкозы и спиртов, растворенных в воде, проходит по приблизительной формуле, учитывающей фотогенерацию электронно-дырочных пар на фотокатализаторе. При наличии в воде нескольких органических соединений, например, глюкозы, органических кислот, каждое их них будет подвергаться разложению при фотокатализе и проходящие реакции будут весьма запутаны, поэтому ниже приведен простейший случай - разложение метанола в воде.

При фотолизе на нанокатализаторе обычной воды происходит ее разложение на кислород и водород по формуле:

$$
2 \mathrm{H}_{2} \mathrm{O} \stackrel{\mathrm{h} v}{\rightarrow} 2 \mathrm{H}_{2}(g)+\mathrm{O}_{2}(g)
$$

Данный процесс, инициированный фотогенерацией на поверхности полупроводника начинается при энергии инжектированных в окружающую среду электрондырочной пары $1.25 \mathrm{eV}$ [10]. В работе [11] показано, что подобный процесс катализа, проходящий в водном растворе спиртов и других органических веществ, приводит к разрушению молекул с выделением метана и далее разрушению до получения водорода после фоторазложения исходного вещества при низкой энергии активации, существенно ниже, чем энергия, необходимая для фотолиза воды. Ниже приведены в качестве примера ожидаемые реакции, проходящие при фотолизе метанола в водном растворе. Реакция проходит с участием воды под действием электронно-дырочных пар, генерируемых на поверхности наночастиц под действием поглощенных квантов света, и приводит к выделению водорода. Более длинные молекулы, такие как сахара, разрываются по связи $\mathrm{C}-\mathrm{C}$, и дальнейшее разложение идет по подобной схеме.

$$
\begin{gathered}
\mathrm{CH}_{3} \mathrm{OH}(l) \leftrightarrow \mathrm{HCHO}(l)+\mathrm{H}_{2}(g), \\
\Delta G_{1}^{\circ}=64 \mathrm{~kJ} / \mathrm{mol}, \\
\mathrm{HCHO}(l)+\mathrm{H}_{2} \mathrm{O}(l) \leftrightarrow \mathrm{HCO}_{2} \mathrm{H}(l)+\mathrm{H}_{2}(g), \\
\Delta G_{2}^{\circ}=47.8 \mathrm{~kJ} / \mathrm{mol}, \\
\mathrm{HCO}_{2} \mathrm{H}(l) \leftrightarrow \mathrm{CO}_{2}(g)+\mathrm{H}_{2}(g), \\
\Delta G_{3}^{\circ}=-95.8 \mathrm{~kJ} / \mathrm{mol}, \\
\mathrm{CH}_{3} \mathrm{OH}(l)+\mathrm{H}_{2} \mathrm{O}(l) \leftrightarrow \mathrm{CO}_{2}(g)+3 \mathrm{H}_{2}(g), \\
\Delta G^{\circ}=16.1 \mathrm{~kJ} / \mathrm{mol} .
\end{gathered}
$$

В соответствии с приведенными реакциями [12], фотокаталитическое разложение метанола приводит к генерации газообразных водорода и окиси углерода, что и является целью водородной энергетики. При этом энергия образования водорода понижается до $0.7 \mathrm{eV}$. По подобным реакциям происходит разложение и других органических соединений.

Главный элемент для реализации процесса - фотокатализатор, основные требования, предьявляемые к которому: необходимая ширина зоны, химическая стойкость, большая удельная поверхность, фиксация на подложке и направленный перенос носителей на подложку. Исходя из перечисленных требований, оптимальным представляется $\mathrm{ZnO}$ в виде нанопроволок, фиксированных на подложке. Фотокатализатор представляет собой нанопроволоки $\mathrm{ZnO}$, выращенные на подложке гидротермальным методом, описанном в общем виде в работе [6]. Процесс основан на разложении $\mathrm{Zn}$ ацетата в растворе в присутствии уротропина по формуле

$$
\begin{gathered}
\left(\mathrm{CH}_{2}\right)_{6} \mathrm{~N}_{4}+6 \mathrm{H}_{2} \mathrm{O} \rightarrow 6 \mathrm{HCHO}+4 \mathrm{NH}_{3}, \\
\mathrm{NH}_{3}+\mathrm{H}_{2} \mathrm{O} \rightarrow \mathrm{NH}_{4}^{+}+\mathrm{OH}^{-}, \\
2 \mathrm{OH}^{-}+\mathrm{Zn}^{2+} \rightarrow \mathrm{Z}(\mathrm{OH})_{2} \rightarrow \mathrm{ZnO}+\mathrm{H}_{2} \mathrm{O} .
\end{gathered}
$$

В данной реакции процесс образования твердого кристаллического безводного $\mathrm{ZnO}$ обусловлен каталитическим разложением, происходящим только на поверхности $\mathrm{ZnO}$, предварительно сформированного на подложке при нанесении на нее ацетата цинка и его разложении 


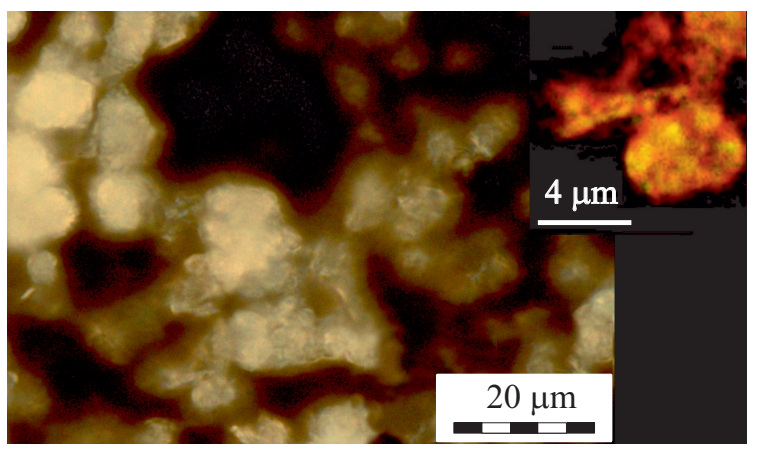

Рис. 2. Микрофотография полученного нанокатализатора $\mathrm{ZnO}$ (поляризационный контраст), на врезке большее увеличение.

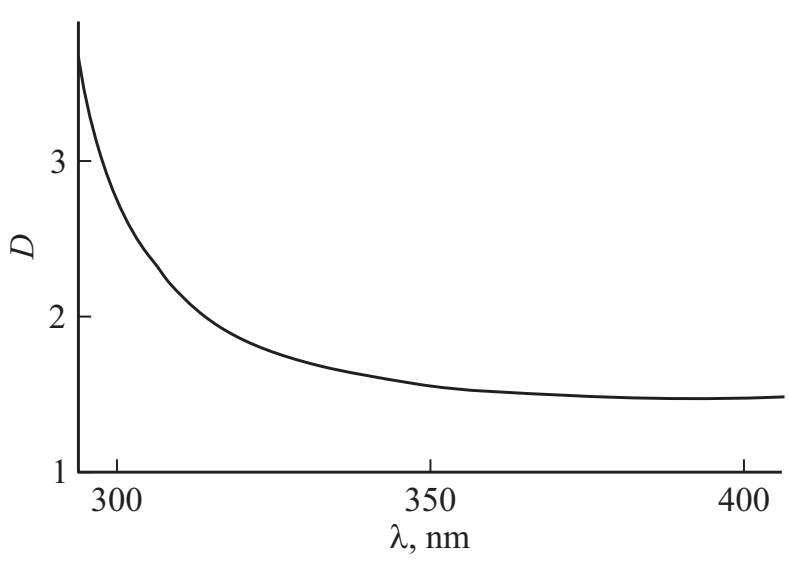

Рис. 3. Спектр поглощения кристаллического $\mathrm{ZnO}$.

при $350^{\circ} \mathrm{C}$. Морфология образующегося $\mathrm{ZnO}$ зависит от температуры проведения процесса и концентрации реагентов.

В эксперименте для выращивания нанопроволок $\mathrm{ZnO}$ использовались подложки из стекла. Перед началом эксперимента подложки подвергались активации в 10\% растворе гидроксида натрия в течение 10 минут. Затем подложки были высушены естественным путем. Подготовили раствор дигидрата ацетата цинка в 1-пропаноле в количестве $5 \mathrm{mM}$, опустили подложки из стекла и использовали метод центрифугирования. Сразу после центрифугирования подложки отжигались при $350^{\circ} \mathrm{C}$ в течение $20 \mathrm{~min}$ для получения слоя нанокристаллов $\mathrm{ZnO}$. Далее подложку помещали в водный раствор дигидрата ацетата цинка $\left[\mathrm{CH}_{3} \mathrm{COO}_{2} \mathrm{Zn} \cdot 2 \mathrm{H}_{2} \mathrm{O}\right]$ и уротропина hexamethylenetetramine [HMTA, $\left(\mathrm{CH}_{2}\right) 6 \mathrm{~N}_{4}$ ] при температуре $100^{\circ} \mathrm{C}$. Далее подложку вынули из раствора, опустили в дистиллированную воду для удаления продуктов реакции: органические материалы и остаточные соли. Далее подложки были помещены в чашку Петри для высушивания.

Полученные кристаллические образования исследовались методами оптической микроскопии и абсорбционной спектрофотометрии. Поскольку толщина слоев составляла не более $5 \mu \mathrm{m}$ на стекле, рентгенострук- турный анализ был неприменим и для подтверждения кристаллической природы использовалось фотографирование в режиме поляризационного контраста. Микрофотография, полученная на микроскопе Olympus STM6 в режиме поляризационного контраста, приведена на рис. 2. Четко видны кристаллические структуры $\mathrm{ZnO}$, которые вращают плоскость поляризации света, что проявляется в ярком их изображении на черном фоне скрещенных поляризаторов. Поскольку кристаллические объекты ZnO представляют собой, вероятно, перепутанные клубки нанонитей, они наблюдаются как бесформенные структуры, имеющие, однако значительную анизотропию. Высота объектов, приведенных на рис. 2, составляет около $5 \mu \mathrm{m}$.

Как видно из спектра, приведенного на рис. 3, поглощение полученных объектов сильно возрастает с уменьшением длины волны короче $350 \mathrm{~nm}$. Спектр подобен известным спектрам поглощения наночастиц $\mathrm{ZnO}$, например, приведенных в работах [13,14]. При возбуждении ультрафиолетовым излучением с длиной волны $365 \mathrm{~nm}$ наблюдалась голубая люминесценция, характерная для $\mathrm{ZnO}$. К сожалению, сильная неравномерность свечения по площади подложки не позволила измерить спектр люминесценции.

Результаты, полученные методами микроскопии и спектрофотомерии, подтверждают образование объектов, вращающих плоскость поляризации света, имеющих спектр поглощения подобный $\mathrm{ZnO}$ и вероятно являющихся кристаллическими клубками нанопроволок $\mathrm{ZnO}$, сформированных на стеклянной подложке. Спутанная неоднородная структура клубков идеальна для применения в качестве полупроводника для фотокатализа.

В дальнейшем предполагается выполнение фотолитического разложения модельных углеводородов: спиртов, сахаров, растворенных в воде данным методом с анализом образующихся продуктов реакции.

\section{Выводы}

На основании анализа литературных данных рассмотрена проблема утилизации сельскохозяйственных отходов переработки овощей в сахар и крахмал, рассмотрено наиболее перспективное ее решение, основанное на фотолитическом разложении спиртов, сахаров, органических кислот на нанокатализаторе с получением водорода в смеси с метаном (биогаз). Рассмотрены возможные химические реакции, сопровождающие фотолитическое разложение на основе спирта и проведены эксперименты по созданию нанокатализатора $\mathrm{ZnO}$, иммобилизованного на подложке с целью проведения фотокаталитического разложения модельных растворов спиртов, сахаров и т.п с целью получения биогаза.

\section{Конфоликт интересов}

Авторы заявляют, что у них нет конфликта интересов. 


\section{Список литературы}

[1] Vaccari G., Tamburini E., Sgualdino G., Urbaniec K., Klemes J. // J. Cleaner Production. 2005. V. 3. N 5. P. 499-507.

[2] Thanh L.T., Okitsu K., Boi L.V., Maeda Y. // Catalysts. 2012. V. 2. N 1. P. 191-222.

[3] Verykios X.E. // International J. Hydrogen Energy. 2003. V. 8. 10. P. $1045-1063$.

[4] Fabrao R.M., de Brito J.F., da Silva J.L., Stradiotto N.R., Zanoni M.V. // Electrochimica Acta. 2016. V. 222. P. $123-132$.

[5] Ge M., Cai J., Iocozzia J., Cao C., Huang J., Zhang X., Shen J., Wang S., Zhang S., Zhang K.-Q., Lai Y., Lin Z. // International Journal of Hydrogen Energy. 2017. V. 42. N 12. P. $8418-8449$.

[6] Akgun M.C., Kalay Y.E., Unalan H.E. // J. Materials Research. 2012. V. 27. N 11. P. 1445-1451.

[7] Beydoun D., Amal R., Low G., McEvoy S. // J. Nanoparticle Research. 1999. V. 1. N 4. P. 439-458.

[8] Denisyuk I.Y., Pozdnyakova S.A., Koryakina I.G., Uspenskaya M.V., Volkova K.V. // Opt. and Spectrosc. 2016. V. 21. N 5. P. $778-781$

[9] Денисюк И.Ю., Пименов Ю.Д. // Возбужденные молекулы. Кинетика превращений Л.: Наука, 1982. С. 234-249.

[10] Bak T., Nowotny J., Rekas M., Sorrell C.C. // Int. J. Hydrogen Energy. 2002. V. 27. P. 991-022.

[11] Chen J., Ollis D.F., Rulkens W.H., Bruning H. // Harry Bruning Water Research. 1999. V. 33. N 3. P. 669-676.

[12] Kim S.B., Lee J.Y., Jang H.T., Cah W.S., Hong S.C. // J. Industrial and Engineering Chemistry. 2003. V. 9. N 4. P. 440-446.

[13] Pesika N.S., Hu Z., Stebe K.J., Searson P.C. // The Journal of Physical Chemistry B. 2002. V. 106. N 28. P. 6985-6990

[14] Vafaee M., Ghamsari M.S. // Materials Letters. 2007. V. 61. N 14-15. P. $3265-3268$. 